\title{
High-level expression of aryl-alcohol oxidase 2 from Pleurotus eryngii in Pichia pastoris for production of fragrances and bioactive precursors
}

\author{
Nina Jankowski ${ }^{1} \cdot$ Katja Koschorreck $^{1} \cdot$ Vlada B. Urlacher $^{1}$ (D) \\ Received: 22 June 2020 / Revised: 14 August 2020 / Accepted: 2 September 2020 / Published online: 19 September 2020 \\ (C) The Author(s) 2020
}

\begin{abstract}
The fungal secretome comprises various oxidative enzymes participating in the degradation of lignocellulosic biomass as a central step in carbon recycling. Among the secreted enzymes, aryl-alcohol oxidases (AAOs) are of interest for biotechnological applications including production of bio-based precursors for plastics, bioactive compounds, and flavors and fragrances. Arylalcohol oxidase 2 (PeAAO2) from the fungus Pleurotus eryngii was heterologously expressed and secreted at one of the highest yields reported so far of $315 \mathrm{mg} / \mathrm{l}$ using the methylotrophic yeast Pichia pastoris (recently reclassified as Komagataella phaffii). The glycosylated $\mathrm{PeAAO} 2$ exhibited a high stability in a broad $\mathrm{pH}$ range between $\mathrm{pH} 3.0$ and 9.0 and high thermal stability up to $55^{\circ} \mathrm{C}$. Substrate screening with 41 compounds revealed that PeAAO2 oxidized typical AAO substrates like $p$-anisyl alcohol, veratryl alcohol, and trans, trans-2,4-hexadienol with up to 8-fold higher activity than benzyl alcohol. Several compounds not yet reported as substrates for AAOs were oxidized by PeAAO2 as well. Among them, cumic alcohol and piperonyl alcohol were oxidized to cuminaldehyde and piperonal with high catalytic efficiencies of 84.1 and $600.2 \mathrm{mM}^{-1} \mathrm{~s}^{-1}$, respectively. While the fragrance and flavor compound piperonal also serves as starting material for agrochemical and pharmaceutical building blocks, various positive health effects have been attributed to cuminaldehyde including anticancer, antidiabetic, and neuroprotective effects. PeAAO2 is thus a promising biocatalyst for biotechnological applications.
\end{abstract}

\section{Key points}

- Aryl-alcohol oxidase PeAAO2 from P. eryngii was produced in P. pastoris at $315 \mathrm{mg} / \mathrm{l}$.

- Purified enzyme exhibited stability over a broad $p H$ and temperature range.

- Oxidation products cuminaldehyde and piperonal are of biotechnological interest.

Keywords Aryl-alcohol oxidase · Pichia pastoris (Komagataella phaffii) · Flavoprotein · Aromatic alcohols · Fragrances · Piperonal

\section{Introduction}

The pursuit of a sustainable and bio-based society includes the search for and development of environmentally friendly production routes for fine chemicals. As a result, more and more

Electronic supplementary material The online version of this article (https://doi.org/10.1007/s00253-020-10878-4) contains supplementary material, which is available to authorized users.

Vlada B. Urlacher

vlada.urlacher@uni-duesseldorf.de

1 Institute of Biochemistry, Heinrich-Heine-University Düsseldorf, Universitätsstraße 1, 40225 Düsseldorf, Germany biocatalytic processes for production of fine chemicals and valuable building blocks are coming into the focus of research and industry. In green chemistry, the use of biocatalysts has many advantages over conventional organic chemical synthesis, including mild reaction conditions (aqueous systems, ambient temperatures, atmospheric pressure), use of catalyst in non-stoichiometric quantities, and reduced waste production (Sheldon and Woodley 2018). Aryl-alcohol oxidases (AAOs, EC 1.1.3.7) are FAD-dependent oxidoreductases secreted by wood-decaying fungi as glycoproteins (Sannia et al. 1991; Varela et al. 2000a, b). They catalyze the oxidation of primary aromatic and aliphatic polyunsaturated alcohols to the corresponding aldehydes while reducing molecular $\mathrm{O}_{2}$ to $\mathrm{H}_{2} \mathrm{O}_{2}$ (Guillén et al. 1992). In some cases, the generated aldehydes 
can be further oxidized to the aromatic acids depending on the degree of hydration via gem-diol formation of the aldehyde (Ferreira et al. 2010). AAOs offer great potential for application in biocatalytic processes, as they only require molecular oxygen for substrate oxidation and generate hydrogen peroxide as byproduct, without the need of added cofactors. In nature, AAOs play an essential role in degradation of lignocellulosic biomass and hence also in carbon recycling. Wooddecaying fungi secrete a whole bunch of oxidative enzymes like laccases, ligninolytic peroxidases, and aryl-alcohol oxidases in order to break down lignin, the most recalcitrant component of lignocellulose (Kirk and Farrell 1987).

While laccases (EC 1.10.3.2) and ligninolytic peroxidases (EC 1.11.1.x) have been intensively studied and applied in different fields including food, textile and cosmetics industry, biorefineries, and bioremediation (Arregui et al. 2019; Falade et al. 2016, 2018; Fillat et al. 2017; Rodríguez Couto and Toca Herrera 2006; Stanzione et al. 2020), $\mathrm{H}_{2} \mathrm{O}_{2}$-producing oxidases like aryl-alcohol oxidases only slowly step forward into biocatalytic applications. For example, an AAO from Pleurotus eryngii ATCC 90787 (PeAAO) was studied for production of 2,5-furandicarboxylic acid (FDCA), a biobased precursor for plastics (Carro et al. 2014; Karich et al. 2018; Serrano et al. 2019a; Viña-Gonzalez et al. 2020). Structure-guided mutagenesis was applied on PeAAO to construct enzyme variants capable of selectively oxidizing secondary aromatic alcohols like $(S)$-1-( $p$-methoxyphenyl)-ethanol to the corresponding ketones (Serrano et al. 2019b; ViñaGonzalez et al. 2019). This enables the use of AAO in kinetic deracemization of secondary alcohols and generation of enantiomer enriched preparations, which are essential building blocks in the production of pharmaceuticals (Patel 2018). The most recent studies regarding enzyme engineering of AAOs and potential applications were summarized by ViñaGonzalez and Alcalde (2020).

In general, most oxidation products of AAO-catalyzed reactions have considerable importance for the flavor and fragrance industry. Recently, PeAAO from $P$. eryngii was employed for the conversion of trans-2-hexenol to the aldehyde trans-2-hexenal, which is of interest for the flavor and fragrance industry as fresh and fruity note of different vegetables and fruits (de Almeida et al. 2019; Van Schie et al. 2018). To gain access to a wider range of pleasant-smelling aldehydes and valuable building blocks via biocatalysis, more information about the substrate scope of AAOs is needed.

One of the factors limiting a broader application and protein engineering of AAOs is their "difficult" expression in recombinant hosts. For instance, the most studied arylalcohol oxidase PeAAO from $P$. eryngii yielded only $3 \mathrm{mg} / 1$ in Aspergillus nidulans (Ferreira et al. 2005). The same enzyme was produced in Escherichia coli as inclusion bodies (Ruiz-Dueñas et al. 2006) and yielded $45 \mathrm{mg} / \mathrm{l}$ after in vitro refolding. However, due to the lack of glycosylation, the
E. coli-derived recombinant $P e \mathrm{AAO}$ showed lower $\mathrm{pH}$ and thermal stability than the recombinant enzyme expressed in A. nidulans (Ruiz-Dueñas et al. 2006). Efforts were made to optimize PeAAO for secretion in eukaryotic hosts. The optimized $P e A A O$ variant FX7 was constructed using the mutagenic organized recombination process by homologous in vivo grouping (MORPHING) for improved expression in Saccharomyces cerevisiae and yielded $2 \mathrm{mg} / \mathrm{l}$ of active hyperglycosylated enzyme (Viña-Gonzalez et al. 2015). This variant was further optimized by in vivo shuffling with other $\mathrm{PeAAO}$ variants and by the targeted MORPHING of the chimeric signal peptide, which eventually led to the variant FX9. This variant was transferred to Pichia pastoris for high-level production, leading to $25.5 \mathrm{mg} / 1$ of enzyme (Viña-Gonzalez et al. 2018). Using a basidiomycete as expression host, an AAO from Pleurotus sapidus was heterologously produced in Coprinopsis cinerea with a yield of $1.4 \mathrm{mg} / 1$ (Galperin et al. 2016). In order to fully elucidate fungal AAOs promising properties as biocatalysts in biotechnological processes, a high-yield expression system needs to be established.

Here, we report on high-yield expression of aryl-alcohol oxidase 2 from $P$. eryngii P34 (PeAAO2) in the methylotrophic yeast $P$. pastoris for biotechnological applications. PeAAO2 was characterized and the activity towards a large set of aromatic, heterocyclic, and aliphatic alcohols was investigated. Several compounds not yet described as substrates for AAOs were oxidized by $\mathrm{PeAAO} 2$ to furnish important products for the flavor and fragrance industry, and bioactive compounds like piperonal and cuminaldehyde. Furthermore, the influence of glycosylation on enzyme stability was investigated, and kinetic parameters were determined for selected substrates to assess the biotechnological potential of this AAO.

\section{Materials and methods}

\section{Materials}

All chemicals were purchased from abcr GmbH (Karlsruhe, Germany), Acros Organics (Geel, Belgium), Alfa Aesar (Kandel, Germany), AppliChem GmbH (Darmstadt, Germany), BLDpharm (Shanghai, China), Carbolution Chemicals GmbH (St. Ingbert, Germany), Carl Roth GmbH + Co. KG (Karlsruhe, Germany), Fluorochem (Hadfield, UK), J\&K Scientific (Lommel, Belgium), Sigma-Aldrich (Schnelldorf, Germany), TCI Chemicals (Eschborn, Germany), and VWR (Darmstadt, Germany). Enzymes and kits were obtained from New England Biolabs (Frankfurt am Main, Germany), Thermo Fisher Scientific (Bremen, Germany), SERVA Electrophoresis GmbH (Heidelberg, Germany), and Zymo Research (Freiburg, Germany). 


\section{Bacterial and yeast strains}

Escherichia coli strain DH5 $\alpha$ used for plasmid amplification was obtained from Clontech Laboratories Inc. (Heidelberg, Germany). Pichia pastoris strain X-33 (recently reclassified as Komagataella phaffii) used for expression was purchased from Invitrogen (Carlsbad, USA).

\section{Generation of recombinant $P$. pastoris X-33 transformants}

The gene encoding for $P e A A O 2$ from the $P$. eryngii strain P34 (GenBank accession number GU444001.1) was identified by protein BLAST search, using the AAO from the $P$. eryngii strain ATCC 90787 (GenBank accession number AAC72747) as query. The gene peaao2 was codon optimized (GenBank accession number MT711371) for the expression in Saccharomyces cerevisiae using the online tool JCat (Grote et al. 2005). The optimized gene carrying the native signal sequence was synthesized by BioCat GmbH (Heidelberg, Germany) and readily ligated into pPICZA vector (Invitrogen, Carlsbad, USA) employing the restriction sites EcoRI and NotI, to generate the plasmid pPICZA_peAAO2. Chemically competent $E$. coli $\mathrm{DH} 5 \alpha$ cells were transformed with the desired plasmid and transformants were selected on low salt lysogeny broth agar plates (LB; $1 \%$ peptone, $0.5 \%$ yeast extract, $0.5 \% \mathrm{NaCl}, 1.5 \%$ agar) containing $25 \mu \mathrm{g} / \mathrm{ml}$ zeocin (InvivoGen, San Diego, USA). A total of $5 \mathrm{ml}$ of LB medium with $25 \mu \mathrm{g} / \mathrm{ml}$ zeocin was inoculated with transformed E. coli cells and cultivated overnight $\left(37^{\circ} \mathrm{C}\right.$ and $180 \mathrm{rpm})$. The plasmids were isolated using the ZR Plasmid Miniprep Kit (Zymo Research, Irvine, USA) according to manufacturer's instructions.

The isolated plasmid pPICZA_PeAAO2 was linearized in the 5'AOX1 region with FastDigest MssI (Thermo Fisher Scientific, Waltham, USA) and used for transformation of electrocompetent $P$. pastoris X-33 cells. Recombinant $P$. pastoris $\mathrm{X}-33$ cells were selected on yeast extract peptone dextrose sorbitol agar plates (YPDS; $1 \%$ yeast extract, $2 \%$ peptone, $2 \%$ dextrose, $1 \mathrm{M}$ sorbitol, $2 \%$ agar) supplemented with $100 \mu \mathrm{g} / \mathrm{ml}$ of zeocin and grown for $4-6$ days at $30^{\circ} \mathrm{C}$.

\section{Enzyme production in shaking flasks}

Several $P$. pastoris transformants with pPICZA peAAO2 integrated into the genome were used for expression in $100 \mathrm{ml}$ shaking flasks. Precultures were grown overnight $\left(30^{\circ} \mathrm{C}\right.$, $200 \mathrm{rpm}$ ) in $10 \mathrm{ml}$ of buffered complex glycerol medium (BMGY; $1 \%$ yeast extract, $2 \%$ peptone, $100 \mathrm{mM}$ potassium phosphate buffer $\mathrm{pH} 6.0,1.34 \%$ yeast nitrogen base without amino acids, $4 \times 10^{-5} \%$ biotin, $1 \%$ glycerol). The precultures were used to inoculate $10 \mathrm{ml}$ of buffered complex methanol medium (BMMY; same as BMGY but without glycerol) to an optical density at $600 \mathrm{~nm}\left(\mathrm{OD}_{600}\right)$ of 1 . The cells were cultivated for 2 days $\left(25^{\circ} \mathrm{C}, 200 \mathrm{rpm}\right)$ with the addition of $0.5 \%$ $(\mathrm{v} / \mathrm{v})$ methanol every $24 \mathrm{~h}$. The $\mathrm{OD}_{600}$ and volumetric activity in the cell-free supernatant towards veratryl alcohol were assayed daily as described below.

\section{Enzyme production in $7.5 \mathrm{I}$ bioreactor}

The best producing $P$. pastoris transformant was used for fedbatch cultivation in a 7.51 bioreactor (Infors, Bottmingen, Switzerland). A total of 31 of fermentation basal salts medium (per 1 1: $0.47 \mathrm{~g} \mathrm{CaSO}_{4} \times 2 \mathrm{H}_{2} \mathrm{O}, 8 \mathrm{ml} \mathrm{H}_{3} \mathrm{PO}_{4}$ (85\%), $9.1 \mathrm{~g}$ $\mathrm{K}_{2} \mathrm{SO}_{4}, 4.2 \mathrm{~g} \mathrm{KOH}, 3.66 \mathrm{~g} \mathrm{MgSO}_{4}, 43.5 \mathrm{~g}$ glycerol (100\%), $0.87 \mathrm{mg}$ biotin, $4.35 \mathrm{ml}$ Pichia trace metals (per 11 of $\mathrm{PTM}_{1}$ solution: $6 \mathrm{~g} \mathrm{CuSO}_{4}$ × $5 \mathrm{H}_{2} \mathrm{O}, 0.08 \mathrm{~g} \mathrm{NaI}, 3 \mathrm{~g} \mathrm{MnSO}_{4}$. $\mathrm{H}_{2} \mathrm{O}$, $0.5 \mathrm{~g} \mathrm{CoCl}_{2}, 20 \mathrm{~g} \mathrm{ZnCl}_{2}, 0.02 \mathrm{~g} \mathrm{H}_{3} \mathrm{BO}_{3}, 0.2 \mathrm{~g} \mathrm{Na}_{2} \mathrm{Mo}_{4} \times 2$ $\mathrm{H}_{2} \mathrm{O}, 65 \mathrm{~g} \mathrm{FeSO}_{4}, 7 \mathrm{H}_{2} \mathrm{O}, 0.2 \mathrm{~g}$ biotin, $\left.5 \mathrm{ml} \mathrm{H}_{2} \mathrm{SO}_{4}\right)$ ) was inoculated to an $\mathrm{OD}_{600}$ of 0.5 from a preculture in $200 \mathrm{ml}$ BMGY medium containing $100 \mu \mathrm{g} / \mathrm{ml}$ zeocin grown over night $\left(30^{\circ} \mathrm{C}, 200 \mathrm{rpm}\right)$. For this, the necessary amount of cells was harvested from the preculture by centrifugation $(1500 \mathrm{xg}$, 5 min, $4{ }^{\circ} \mathrm{C}$ ) and resuspended in sterile $0.9 \%$ sodium chloride solution for inoculation of the fermentation medium. Oxygen was supplied with a rate of $3 \mathrm{l} / \mathrm{min}$ and the stirring rate was $800 \mathrm{rpm}$. The $\mathrm{pH}$ was kept at $\mathrm{pH} 5.0$ by titrating $10 \%$ phosphoric acid or $25 \%$ ammonium hydroxide and the temperature was set to $30{ }^{\circ} \mathrm{C}$. After full consumption of glycerol, a $\mathrm{pO}_{2}$ spike controlled fed-batch started with methanol as inducer and sole carbon source. Methanol was added automatically to $0.5 \%\left(\mathrm{v} / \mathrm{v}\right.$; with $12 \mathrm{~g} / 1 \mathrm{PTM}_{1}$ solution) when a sharp increase in $\mathrm{pO}_{2}$ indicated depletion of the carbon source. After induction, the temperature was reduced to $25^{\circ} \mathrm{C}$ and the fermentation was continued for a total of 9 days with daily sampling to monitor $\mathrm{OD}_{600}$, volumetric activity towards veratryl alcohol, and protein concentration in the cell-free supernatant.

\section{Protein purification}

The collected fermentation broth was centrifuged $(11,325 \times g$, $15 \mathrm{~min}, 4{ }^{\circ} \mathrm{C}$ ) and the cell-free supernatant was concentrated and rebuffered in $50 \mathrm{mM}$ potassium phosphate $\mathrm{pH} 6.0$ using tangential flow filtration (TFF) with three membranes (10 kDa molecular cut-off, Pall, Port Washington, USA).

$\mathrm{PeAAO} 2$ was purified by three chromatographic steps. For hydrophobic interaction chromatography (HIC), $2 \mathrm{M}$ of ammonium sulfate (solid) was added to $10 \mathrm{ml}$ of the concentrated supernatant and dissolved at $10^{\circ} \mathrm{C}$ and rotation overnight. The sample was centrifuged $\left(18,000 \times g, 30 \mathrm{~min}, 4^{\circ} \mathrm{C}\right)$ and filtered using a $0.45-\mu \mathrm{m}$ pore size filter. A XK16/20 column with Butyl Sepharose HP medium $(20 \mathrm{ml}$, GE Healthcare, Chicago, USA) connected to an ÄKTApurifier FPLCsystem (GE Healthcare, Chicago, USA) was equilibrated with $50 \mathrm{mM}$ potassium phosphate buffer $\mathrm{pH} 6.0$ with $1.5 \mathrm{M}$ 
ammonium sulfate (eluent B). A total of $10 \mathrm{ml}$ of sample was loaded onto the column and washed for two column volumes $(\mathrm{CV})$ with eluent $\mathrm{B}$ and a flow rate of $1.5 \mathrm{ml} / \mathrm{min}$. Proteins were eluted using a step gradient with decreasing concentrations of eluent $\mathrm{B}$ by mixing with $50 \mathrm{mM}$ potassium phosphate buffer $\mathrm{pH} 6.0$ (eluent $\mathrm{A}$ ). Foreign proteins were removed with two CV of $70 \%$ eluent $\mathrm{B}$, and PeAAO2 was eluted with three CV of $40 \%$ eluent B. Fractions showing activity towards veratryl alcohol were pooled, concentrated, and desalted using a Vivaspin Turbo 15 ultrafiltration unit $(10 \mathrm{kDa}$ molecular cut-off, Sartorius, Göttingen, Germany). The concentrated HIC sample was used for ion exchange chromatography (IEX) using a XK16/20 column packed with DEAE Sepharose FF medium (29 ml, GE Healthcare, Chicago, USA). The column was equilibrated with $50 \mathrm{mM}$ potassium phosphate buffer $\mathrm{pH} 6.0$ (eluent A) and proteins were eluted with increasing amounts of $50 \mathrm{mM}$ potassium phosphate buffer pH 6.0 with $1 \mathrm{M}$ sodium chloride (eluent B) at a flow rate of $1.5 \mathrm{ml} / \mathrm{min}$. A linear gradient of $0-30 \%$ eluent $\mathrm{B}$ for five $\mathrm{CV}$ was used to elute $\mathrm{PeAAO} 2$. Again, the active fractions were pooled and concentrated. At last, the concentrated sample was applied to a Superdex 200 Increase 10/300 GL column (24 ml, GE Healthcare, Chicago, USA) for size exclusion chromatography (SEC). Using an isocratic gradient of one $\mathrm{CV}$ of $50 \mathrm{mM}$ potassium phosphate buffer $\mathrm{pH} 6.0$ with $150 \mathrm{mM}$ sodium chloride at a flow rate of $0.25 \mathrm{ml} / \mathrm{min}, P e A A O 2$ was eluted and active fractions were pooled, concentrated, and desalted as described above. Purified $\mathrm{PeAAO} 2$ was stored at $4{ }^{\circ} \mathrm{C}$ until use.

\section{Biochemical characterization}

Protein concentration was determined by the Bradford method (Bradford 1976) with bovine serum albumin (BSA) as standard.

Glycosylation extent was analyzed by employing Peptide$\mathrm{N}$-amidase PNGase F (New England Biolabs, Frankfurt am Main, Germany) to deglycosylate $20 \mu \mathrm{g}$ of purified PeAAO2 according to the manufacturer's protocol. The deglycosylation was carried out under denaturing as well as under native conditions (for up to $96 \mathrm{~h}$ ) to investigate the influence of glycosylation on activity and thermal stability of PeAAO2. The resulting deglycosylated protein was analyzed via SDSpolyacrylamide gel electrophoresis (SDS-PAGE). SDSPAGE with purified enzyme samples was carried out following the protocol of Laemmli (1970) with $12.5 \%$ resolving gel. The gels were stained with Coomassie Brilliant Blue R250.

\section{Spectroscopic analysis}

All measurements were performed at $25{ }^{\circ} \mathrm{C}$ with $2 \mathrm{mg} / \mathrm{ml}$ purified $\mathrm{PeAAO} 2$ in $50 \mathrm{mM}$ potassium phosphate buffer pH 6.0 using a Lambda 35 spectrophotometer (Perkin
Elmer, Waltham, USA). The molar extinction coefficient of $P e A A O 2$ was calculated on the basis of released FAD cofactor from the purified enzyme after heat denaturation as reported elsewhere (Aliverti et al. 1999). PeAAO2 was subjected to heat denaturation for $10 \mathrm{~min}$ at $80^{\circ} \mathrm{C}$. Precipitated protein was removed by centrifugation and the absorbance of extracted FAD was measured. The molar extinction coefficient of $P e \mathrm{AAO} 2$ at $463 \mathrm{~nm}$ was calculated on the basis of the equation $\varepsilon_{463}=\varepsilon_{\mathrm{FAD}} * A_{463} / A_{450}$ with $\varepsilon_{\mathrm{FAD}}=11,300 \mathrm{M}^{-1} \mathrm{~cm}^{-1}$ and $A_{463}$ being the absorbance of $P e \mathrm{AAO} 2$ before heat denaturation and $A_{450}$ of released FAD after heat denaturation.

\section{Enzymatic activity assay}

The routinely used assay for determination of aryl-alcohol oxidase activity was carried out with veratryl alcohol as substrate. The measurements were conducted at room temperature in triplicates using 1-ml cuvettes with $800 \mu \mathrm{l}$ of $100 \mathrm{mM}$ sodium phosphate buffer $\mathrm{pH} 6.0$ and $100 \mu \mathrm{l}$ of $50 \mathrm{mM}$ veratryl alcohol. A total of $100 \mu$ l of appropriately diluted PeAAO2 in $50 \mathrm{mM}$ potassium phosphate buffer $\mathrm{pH} 6.0$ was added to start the reaction. Formation of veratraldehyde $\left(\varepsilon_{310}=\right.$ $9300 \mathrm{M}^{-1} \mathrm{~cm}^{-1}$ ) (Guillén et al. 1992) was followed at $310 \mathrm{~nm}$ using an Ultrospec 7000 photometer (GE Healthcare, Chicago, USA). One unit of activity is defined as the amount of enzyme that converts $1 \mu \mathrm{mol}$ substrate per minute under the stated conditions.

\section{Influence of pH and temperature on stability}

Purified $\mathrm{PeAAO} 2$ was incubated at different $\mathrm{pH}$ values ranging from $\mathrm{pH} 2.0$ to 12.0 (at room temperature) using $100 \mathrm{mM}$ Britton-Robinson buffer or at different temperatures between 4 and $80{ }^{\circ} \mathrm{C}$ in $50 \mathrm{mM}$ potassium phosphate buffer at $\mathrm{pH} 6.0$ for up to $1 \mathrm{~h}$. Samples were taken after certain time points, incubated on ice for $5 \mathrm{~min}$ (in case of thermal stability) and the residual activity towards veratryl alcohol was determined. The activity assay was conducted in triplicates in microtiter plates with $20 \mu \mathrm{l}$ of $P e A A O 2$ containing sample, $20 \mu \mathrm{l}$ of $50 \mathrm{mM}$ veratryl alcohol, and $160 \mu \mathrm{l}$ of $100 \mathrm{mM}$ sodium phosphate buffer $\mathrm{pH}$ 6.0. The product formation was followed at $310 \mathrm{~nm}$ using an Infinite M200 Pro plate reader (Tecan, Männedorf, Switzerland). For determination of $T_{50}$, the temperature at which the enzyme loses $50 \%$ of activity, PeAAO2 was incubated at temperatures ranging from 45 to $75^{\circ} \mathrm{C}$ for $10 \mathrm{~min}$. Afterwards, the samples were cooled on ice for 10 min before measuring the residual activity towards veratryl alcohol as stated above. The resulting data set was plotted using the program OriginPro 9.0 (OriginLab Corporation, Northampton, MA, USA) and the $T_{50}$ value was determined by fitting the data using the Boltzmann equation. 


\section{Determination of melting temperature}

To identify the melting temperature $\left(T_{\mathrm{M}}\right)$ of purified and of natively $\mathrm{N}$-deglycosylated $\mathrm{PeAAO} 2$, the change of intrinsic FAD cofactor fluorescence was monitored in dependence of temperature as employed in the ThermoFAD assay (Forneris et al. 2009). $P e A A O 2$ was diluted in $50 \mathrm{mM}$ potassium phosphate buffer $\mathrm{pH} 6.0$ to $1 \mathrm{mg} / \mathrm{ml}$ and $25 \mu$ lof diluted sample (in triplicate) was used to monitor the fluorescence at different temperatures using qPCR cycler qTOWER ${ }^{3}$ (Analytik Jena, Jena, Germany). Excitation wavelength was set to $470 \mathrm{~nm}$ and emission wavelength to $520 \mathrm{~nm}$ using the SYBR Green fluorescence filter. A temperature gradient from 15 to $95{ }^{\circ} \mathrm{C}$ in $0.5^{\circ} \mathrm{C}$ increments after $15 \mathrm{~s}$ delay was used. The first derivative of the melting curve was calculated using the program OriginPro 9.0 and the $T_{\mathrm{M}}$ value was extracted as maximum of the first derivative.

\section{Investigation of substrate spectrum}

Activity of $P e \mathrm{AAO} 2$ towards 41 compounds was tested in a coupled assay making use of the generated hydrogen peroxide as product of AAO activity. The coupled system included horseradish peroxidase (HRP, Type VI, Sigma-Aldrich, Schnelldorf, Germany) and 2,2'-azino-bis(3-ethylbenzothiazoline-6-sulphonic acid) (ABTS). The measurements were conducted in triplicates in 96-well plates in a total volume of $200 \mu \mathrm{l}$ at room temperature. For this, $20 \mu \mathrm{l}$ of a suitable PeAAO2 dilution was mixed with $20 \mu \mathrm{l}$ of $10 \mathrm{mM}$ substrate (with residual percentage of appropriate organic solvent, see Supplemental Table S1), $20 \mu \mathrm{l}$ of $50 \mathrm{mM}$ ABTS, $20 \mu \mathrm{l}$ of $1 \mathrm{mg} / \mathrm{ml} \mathrm{HRP}$, and $120 \mu \mathrm{l}$ of $100 \mathrm{mM}$ potassium phosphate buffer $\mathrm{pH}$ 6.0. Oxidation of ABTS by HRP in the presence of hydrogen peroxide was followed spectrophotometrically at $420 \mathrm{~nm}$ for $3 \mathrm{~m}\left(\varepsilon_{420}=36,000 \mathrm{M}^{-1} \mathrm{~cm}^{-1}\right)$ (Childs and Bardsley 1975) using an Infinite M200 Pro plate reader (Tecan, Männedorf, Switzerland).

\section{Determination of kinetic constants}

Kinetic constants $V_{\max }$ and $K_{\mathrm{M}}$ were determined for selected substrates at varying concentrations at $25^{\circ} \mathrm{C}$ in $100 \mathrm{mM}$ sodium phosphate buffer $\mathrm{pH} 6.0$ in triplicates in a UV-Star ${ }^{\circledR} 96-$ well micro titer plate (Greiner Bio-One $\mathrm{GmbH}$, Frickenhausen, Germany) with $200 \mu \mathrm{l}$ assay volume using an Infinite M200 Pro plate reader (Tecan, Männedorf, Switzerland). The tested substrates were $p$-anisyl alcohol $(0.98 \mu \mathrm{M}$ to $1 \mathrm{mM})$, benzyl alcohol $(9.8 \mu \mathrm{M}$ to $10 \mathrm{mM})$, cinnamyl alcohol $(9.8 \mu \mathrm{M}$ to $20 \mathrm{mM}$ in DMSO), cumic alcohol $(9.8 \mu \mathrm{M}$ to $10 \mathrm{mM})$, trans,trans-2,4-hexadienol $(0.98 \mu \mathrm{M}$ to $1.75 \mathrm{mM})$, piperonyl alcohol $(0.98 \mu \mathrm{M}$ to $1 \mathrm{mM})$, and veratryl alcohol $(9.8 \mu \mathrm{M}$ to $10 \mathrm{mM}$ ). The molar extinction coefficients used for calculation were $p$-anisaldehyde $\varepsilon_{285}=16,980 \mathrm{M}^{-1} \mathrm{~cm}^{-1}$ (Guillén et al.
1992), benzaldehyde $\varepsilon_{250}=13,800 \mathrm{M}^{-1} \mathrm{~cm}^{-1}$ (Guillén et al. 1992), cinnamaldehyde $\varepsilon_{310}=15,600 \mathrm{M}^{-1} \mathrm{~cm}^{-1}$ (Ferreira et al. 2005), veratraldehyde $\varepsilon_{310}=9300 \mathrm{M}^{-1} \mathrm{~cm}^{-1}$, and trans,trans-2,4-hexadienal $\varepsilon_{280}=30,140 \mathrm{M}^{-1} \mathrm{~cm}^{-1}$ (RuizDueñas et al. 2006). The molar extinction coefficients of cuminaldehyde $\left(\varepsilon_{262}=2920 \mathrm{M}^{-1} \mathrm{~cm}^{-1}\right)$ and piperonal $\left(\varepsilon_{317}=\right.$ $8680 \mathrm{M}^{-1} \mathrm{~cm}^{-1}$ ) were determined as shown in the Supplemental Figs. S1, S2, S3 and S4. Results were analyzed using OriginPro 9.0. A non-linear regression using the Michaelis-Menten equation was conducted to yield the maximum rate $V_{\max }$ and the Michaelis constant $K_{\mathrm{M}}$, and led to the calculation of the rate constant $k_{\text {cat }}$ and catalytic efficiency $k_{\text {cat }} /$ $K_{\mathrm{M}}$ based on the molar concentration as determined by using the calculated molar extinction coefficient of PeAAO2.

\section{Results}

\section{Enzyme production and purification}

The $P$. pastoris (K. phaffii) expression vector pPICZA harboring the codon-optimized peaao 2 gene with its native signal sequence under control of the methanol inducible $\mathrm{P}_{\mathrm{AOX} 1}$ promoter was integrated into the genome of $P$. pastoris $\mathrm{X}-33$ by homologous recombination. Six $P$. pastoris transformants were screened for secretion of active PeAAO2 in BMMY medium in shaking flasks. After 2 days of expression, the volumetric activities towards veratryl alcohol ranged from 18.4 to $74.0 \mathrm{U} / 1$ for different transformants. The P. pastoris transformant with the highest volumetric activity was subsequently used for enzyme production in a 7.5-1 bioreactor. After 9 days of fed-batch cultivation, the $\mathrm{OD}_{600}$ of the culture reached its maximum at 389 accompanied by a volumetric activity of $7250 \mathrm{U} / 1$ at a protein concentration of $1.4 \mathrm{~g} / 1$ (Fig. 1).

After cell separation and supernatant concentration by tangential flow filtration (TFF), recombinant $P e A A O 2$ was purified to homogeneity in a three-step purification procedure, including hydrophobic interaction (HIC), ion exchange (IEX), and size exclusion chromatography (SEC) (Table 1). The purified enzyme showed a specific activity of $23.0 \mathrm{U} / \mathrm{mg}$ towards veratryl alcohol, and was strongly yellow in color and slightly viscous. The expression yield calculated on the basis of specific activity of $P e A A O 2$ was $315 \mathrm{mg} / \mathrm{l}$ of culture.

Native PAGE demonstrated that purified PeAAO2 is present in solution as monomer (Supplemental Fig. S5). SDSPAGE analysis of purified PeAAO2 revealed a strong band at around $100 \mathrm{kDa}$ (Fig. 2). The theoretical molecular weight of $P e \mathrm{AAO} 2$ without signal peptide (first 27 amino acids; the same signal peptide as of the closely related PeAAO, Varela et al. 1999) was predicted to be $60.8 \mathrm{kDa}$ (using Protparam ExPAsy) (Gasteiger et al. 2005). After $N$-deglycosylation using PNGase F, a shift of mobility to around $70 \mathrm{kDa}$ was 
Fig. 1 Fed-batch cultivation of recombinant $P$. pastoris $\mathrm{X}-33$ in a 7.5-1 bioreactor to produce PeAAO2. Squares: $\mathrm{OD}_{600}$ values; circles: volumetric activity (U/1) in cell-free supernatant; triangles: protein concentration $(\mathrm{g} / \mathrm{l})$. All measurements were done in triplicate

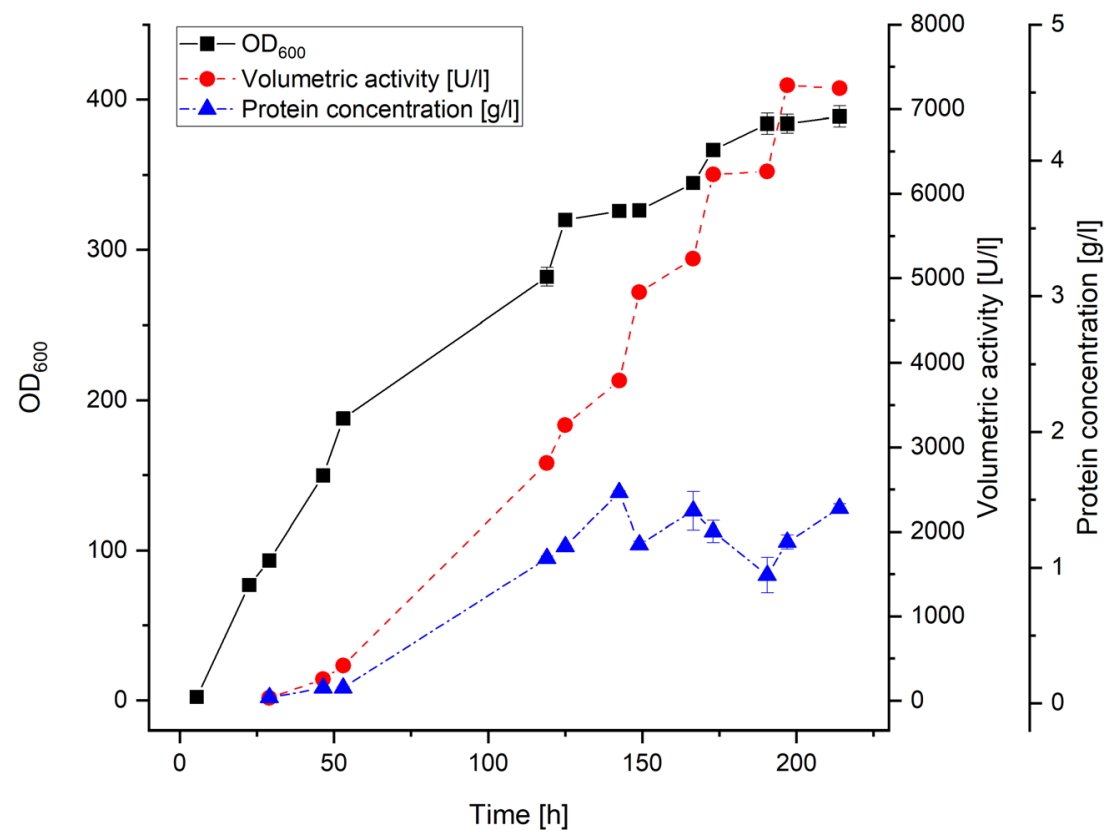

observed, indicating at least 30\% N-glycosylation of heterologously expressed $\mathrm{PeAAO} 2$ (Fig. 2).

The purified $P e A A O 2$ was analyzed in terms of its spectroscopic properties (Fig. 3). The oxidized enzyme showed two maxima at $376 \mathrm{~nm}$ and $463 \mathrm{~nm}$. The extracted FAD showed two pronounced maxima at $376 \mathrm{~nm}$ and $450 \mathrm{~nm}$. The estimated molar extinction coefficient of PeAAO2 at $463 \mathrm{~nm}\left(\varepsilon_{463}\right)$ was $7029 \mathrm{M}^{-1} \mathrm{~cm}^{-1}$.

\section{Influence of $\mathrm{pH}$, temperature, and glycosylation on enzyme stability}

$\mathrm{pH}$ stability of $\mathrm{PeAAO} 2$ was investigated at various $\mathrm{pH}$ values between 2.0 and 12.0 and the enzyme remained stable over a wide range from $\mathrm{pH} 3.0$ to 9.0 with residual activities of around $90 \%$ after $1 \mathrm{~h}$ incubation at room temperature
(Fig. 4a), while a total loss of activity at $\mathrm{pH} 2.0$ and $\mathrm{pH} 11.0$ after $1 \mathrm{~h}$ incubation was observed. Thermal stability of $P e A A O 2$ was studied at temperatures between 4 and $80{ }^{\circ} \mathrm{C}$ for up to $1 \mathrm{~h}$ incubation at $\mathrm{pH}$ 6.0. PeAAO2 was stable from 4 to $50{ }^{\circ} \mathrm{C}$ with residual activities of around $90 \%$, while residual activity dropped to $70 \%$ and $10 \%$ after $1 \mathrm{~h}$ of incubation at $55^{\circ} \mathrm{C}$ and $60{ }^{\circ} \mathrm{C}$, respectively (Fig. $4 \mathrm{~b}$ ).

The temperatures at which half of the activity of PeAAO2 was lost after $10 \mathrm{~min}$ of incubation $\left(T_{50}\right)$ and the melting temperature $\left(T_{\mathrm{M}}\right)$ of $\mathrm{PeAAO} 2$ were determined as well. PeAAO2 showed a $T_{50}$ value of $62.1{ }^{\circ} \mathrm{C}$, while the $T_{\mathrm{M}}$ value was $65.5^{\circ} \mathrm{C}$. For natively $N$-deglycosylated $\mathrm{PeAAO} 2$, a $T_{\mathrm{M}}$ value of $57.0{ }^{\circ} \mathrm{C}$ was measured. The deglycosylated enzyme showed a residual activity of 98.5\% as compared with $\mathrm{PeAAO} 2$ incubated under the same conditions but without PNGase F.

Table 1 Purification of recombinant $\mathrm{PeAAO} 2$

\begin{tabular}{|c|c|c|c|c|c|}
\hline Purification step & Total protein $(\mathrm{mg})^{\mathrm{c}}$ & Total activity $(\mathrm{U})^{\mathrm{d}}$ & Specific activity (U/mg) & Yield $(\%)^{\mathrm{e}}$ & Purity (x-fold) \\
\hline Supernatant $\mathrm{t}^{\mathrm{a}}$ & 5030 & 25,400 & 5.0 & - & 1.0 \\
\hline TFF 1st eluate ${ }^{b}$ & 860 & 10,200 & 11.8 & 100 & 2.3 \\
\hline Butyl Sepharose HP & 50 & 648 & 13.0 & 64 & 2.6 \\
\hline DEAE Sepharose HP & 26.4 & 439 & 16.6 & 43 & 3.3 \\
\hline Superdex 200 increase & 12.6 & 291 & 23.0 & 29 & 4.6 \\
\hline
\end{tabular}

${ }^{\text {a }}$ Cell-free supernatant after centrifugation of fermentation broth

${ }^{\mathrm{b}}$ Ultrafiltration retentate of supernatant using tangential flow filtration (TFF). Concentrated sample was collected in three steps (eluates) with different enzyme activities and protein concentrations. Only the first eluate was used for chromatographic purifications. Hence the apparent loss of activity

${ }^{\mathrm{c}}$ Protein concentration was estimated by Bradford assay with BSA as standard

${ }^{\mathrm{d}}$ Enzyme activity was measured with veratryl alcohol

${ }^{\mathrm{e}}$ Yield based on $10 \mathrm{ml}$ of the 1st eluate applied to Butyl Sepharose HP 


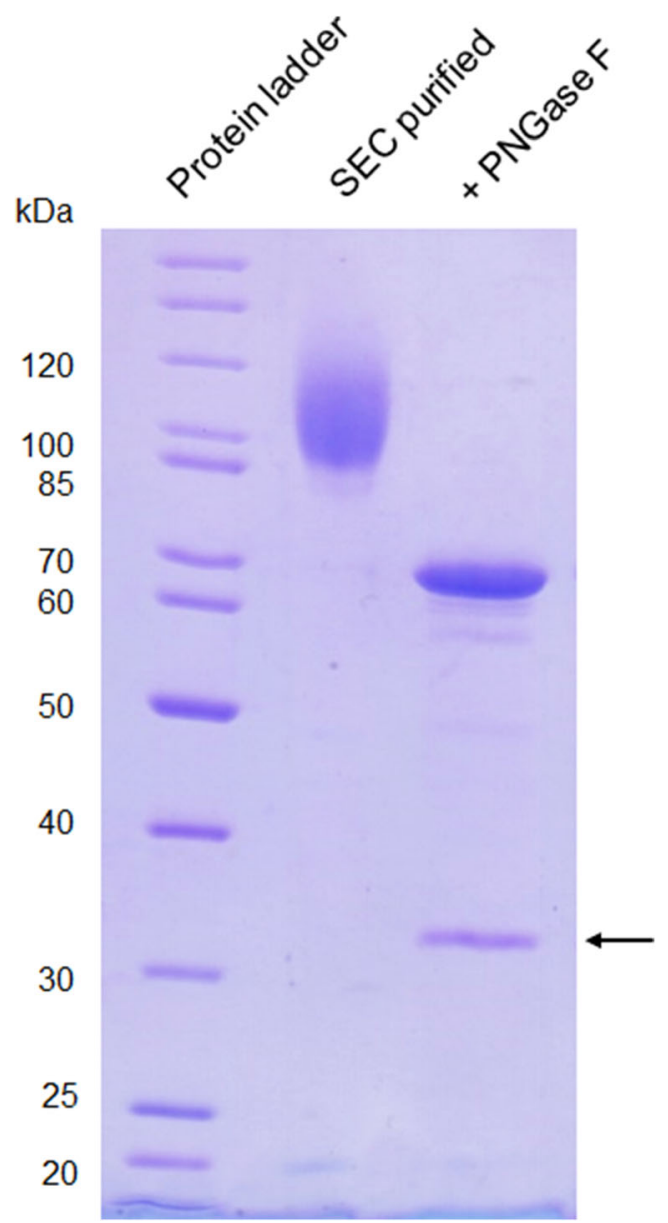

Fig. 2 SDS-PAGE analysis of purified $\mathrm{PeAAO} 2$ and PNGase $\mathrm{F}$ treated PeAAO2. A total of $5 \mu \mathrm{g}$ of each sample was loaded and separated in a $12.5 \%$ resolving gel. Arrow indicates PNGase F (36 kDa)

\section{Substrate spectrum}

A coupled colorimetric assay using ABTS and HRP to measure hydrogen peroxide produced by AAO upon substrate oxidation was used to determine the substrate spectrum of PeAAO2. A total of 41 compounds, some of which have been described as aryl-alcohol oxidase substrates including benzylic, other cyclic, heterocyclic, and aliphatic alcohols, were investigated (Table 2). The activity towards benzyl alcohol was set to $100 \%$. Benzylic alcohols methoxylated in para-position like $p$-anisyl alcohol (647\%), veratryl alcohol (322\%), and isovanillyl alcohol (246\%) were much better substrates than benzyl alcohol. The presence of an extended unsaturated side chain as in cinnamyl alcohol increased activity as well $(442 \%)$. The enzyme showed the highest relative activity of $874 \%$ towards bicyclic 2-naphthalenemethanol, followed by the aliphatic and unsaturated trans,trans-2,4-hexadienol and trans,trans-2,4-heptadienol with $807 \%$ and $737 \%$, respectively. Also, the heterocyclic benzodioxol derivative piperonyl alcohol was accepted by $\mathrm{PeAAO} 2$ and oxidized with a relative activity of $301 \%$, while with the isopropyl substituted benzylic alcohol - cumic alcohol, a relative activity of $149 \%$ was reached. All other tested compounds were "worse" substrates for $\mathrm{PeAAO} 2$ and led to lower relative activities compared to benzyl alcohol. Amino substituted 3- and 4-aminobenzyl alcohols were oxidized with relative activities of 9.4 and $18.6 \%$, respectively, while nitrogen-containing heterocyclic compounds like pyridine and indole derivatives were converted with relative activities of $2 \%$ or below. Among the unsaturated aliphatic alcohols, trans-2-hexenol (64\%), trans-2-heptenol (32\%), trans-2-octenol (5.2\%), and trans-2-cis-6-nonadienol $(3.3 \%)$ were oxidized. The investigated branched aliphatic
Fig. 3 UV-Vis spectrum of purified $P e A A O 2$. Solid line: native $P e \mathrm{AAO} 2$ in its oxidized form; dashed line: extracted FAD after heat denaturation

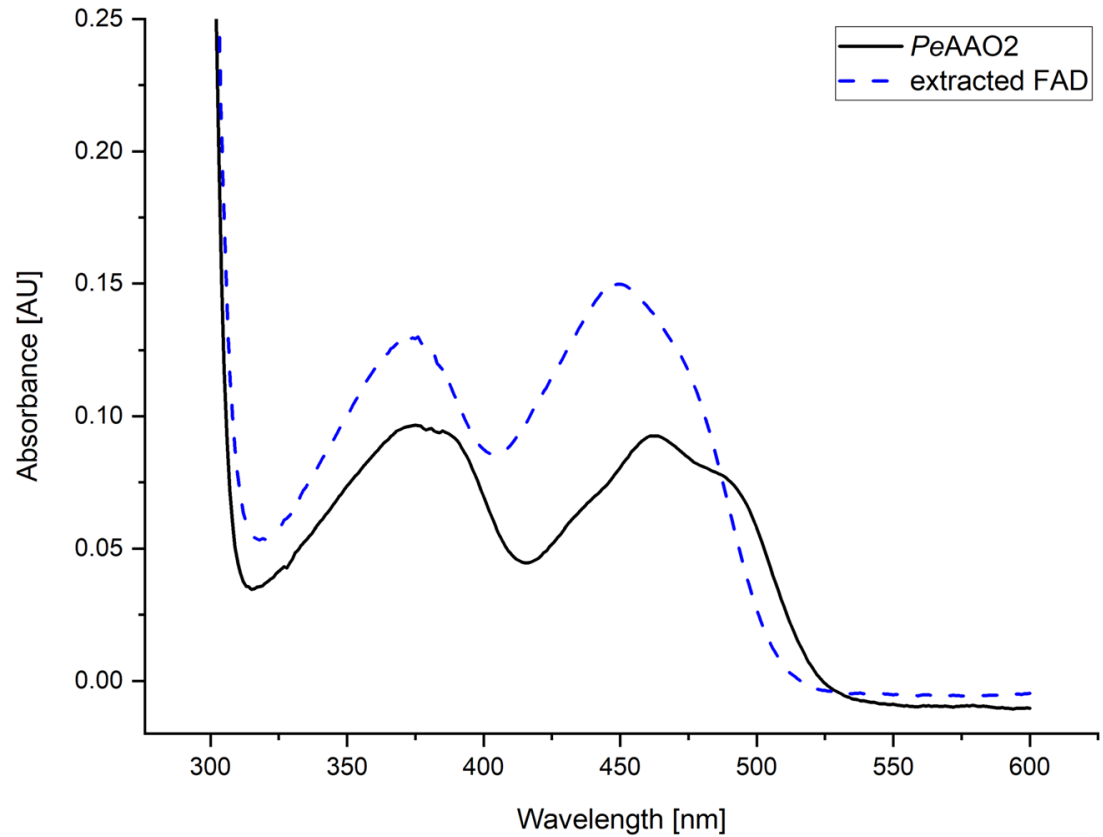




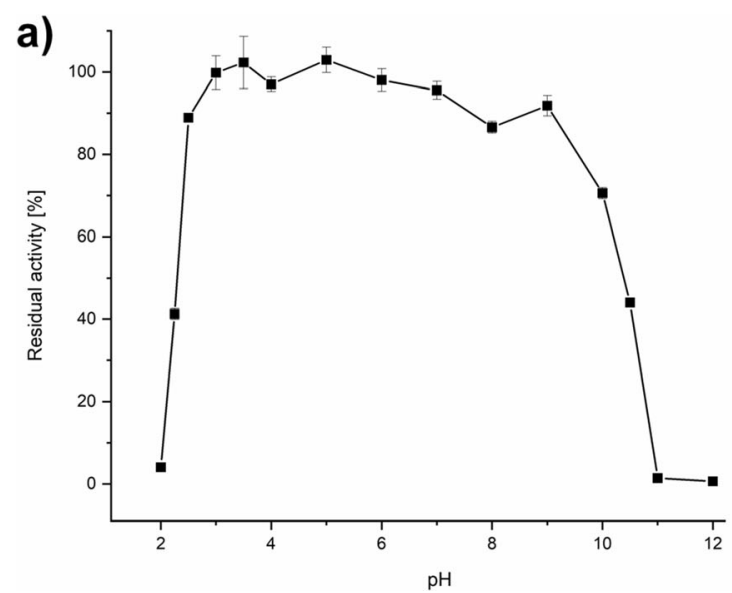

Fig. 4 Influence of $\mathrm{pH}$ and temperature on stability of $P e \mathrm{AAO} 2 . \mathbf{a} \mathrm{pH}$ stability was determined in $100 \mathrm{mM}$ Britton-Robinson buffer at the corresponding $\mathrm{pH}$ for $1 \mathrm{~h}$ at room temperature. b Thermal stability was

alcohols were only accepted to a very small extent as compared with benzyl alcohol, with relative activities generally below $5 \%$.

\section{Kinetic constants}

Kinetic constants $K_{\mathrm{M}}, k_{\text {cat }}$, and $k_{\text {cat }} / K_{\mathrm{M}}$ of PeAAO2 for some of the substrates identified during substrate screening were determined at pH 6.0 (Table 3), at which PeAAO2 showed the highest activity (Supplemental Fig. S6). PeAAO2 showed the highest affinity $\left(K_{\mathrm{M}}\right)$ towards $p$-anisyl alcohol with $24.3 \mu \mathrm{M}$ followed by piperonyl alcohol with $59.1 \mu \mathrm{M}$ and the lowest affinity was found for cinnamyl alcohol with $1912 \mu \mathrm{M}$. The highest catalytic efficiencies $\left(k_{\text {cat }} / K_{\mathrm{M}}\right)$ with $2436 \mathrm{mM}^{-1} \mathrm{~s}^{-1}$ and $600.2 \mathrm{mM}^{-1} \mathrm{~s}^{-1}$ were also estimated for $p$-anisyl alcohol and piperonyl alcohol. Using cumic alcohol as substrate, the highest turnover rate $\left(k_{\text {cat }}\right)$ was observed with $160.8 \mathrm{~s}^{-1}$, which is 4-fold higher than for benzyl alcohol.

\section{Discussion}

\section{Enzyme production and properties}

The efficient utilization of AAOs in biocatalytic processes is mainly hampered due to the lack of highyield expression systems. Our attempts to express the well-examined PeAAO from P. eryngii ATCC 90787 in $P$. pastoris led to no detectable activity (unpublished data), while the expression level of PeAAO2 from $P$. eryngii $P 34$ reached $315 \mathrm{mg} / \mathrm{l}$ and exceeded that of the in $P$. pastoris expressible and "engineered" variant PeAAO FX9 with $25.5 \mathrm{mg} / \mathrm{l}$ by factor 12 (ViñaGonzalez et al. 2018). Thus, PeAAO2 is the best expressed Pleurotus AAO in $P$. pastoris described so far. PeAAO2 and PeAAO differ in seven amino acid

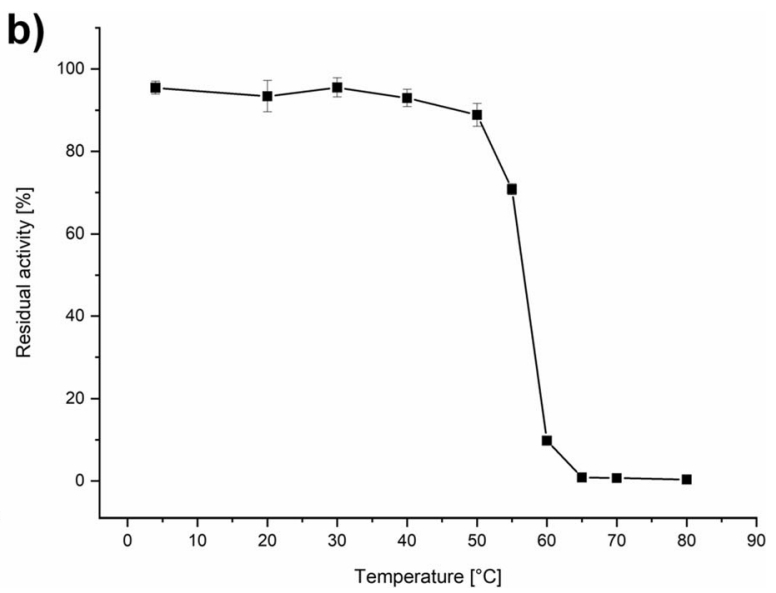

investigated from 4 to $80{ }^{\circ} \mathrm{C}$ in $50 \mathrm{mM}$ potassium phosphate buffer $\mathrm{pH} 6.0$ for $1 \mathrm{~h}$. Residual activity is given in \% of initial activity without incubation

positions located on or near the surface of the protein (Supplemental Fig. S7 and S8). The active site including the two catalytic active histidine residues (His529 and His573 (Ferreira et al. 2006)) and the hydrophobic substrate access channel (Tyr119, Phe424, and Phe528 (Fernández et al. 2009)) are identical in both enzymes, but an additional potential $N$-glycosylation site (Asn361$\mathrm{X}$-Ser) is present in PeAAO2. Which of the amino acid variations leads to (high) expression of PeAAO2 in $P$. pastoris as compared with $P e A A O$ remains questionable and is under further investigation.

PeAAO2 contains eight potential $N$-glycosylation sites (Asn-X-Thr/Ser, where $\mathrm{X}$ is any amino acid except for proline) (Kukuruzinska et al. 1987) at the residues Asn89, Asn165, Asn178, Asn249, Asn336, Asn352, Asn361, and Asn396 (Supplemental Fig. S7). The discrepancy in molecular weight of PeAAO2 with a theoretical molecular weight without signal peptide of $60.8 \mathrm{kDa}$ and $100 \mathrm{kDa}$ observed via SDS-PAGE is due to $N$ - and $O$-glycosylation performed by $P$. pastoris. The $N$-deglycosylated enzyme showed a sharp band at $70 \mathrm{kDa}$, indicating $30 \%$ of $N$-glycosylation extent in recombinantly produced PeAAO2, while $10 \% O$-glycosylation is assumed. This value is higher than the carbohydrate content described for homologously produced PeAAO with 14\% (Varela et al. 2000b). Interestingly, the PeAAO variant FX9 expressed in $P$. pastoris was poorly glycosylated, despite the presence of seven potential $N$-glycosylation sites (Viña-Gonzalez et al. 2018).

The $N$-deglycosylated $P e A A O 2$ retained its activity after deglycosylation, implying that glycosylation is not necessary for enzymatic activity, but rather positively affects enzyme thermostability. The glycosylated PeAAO2 showed a $9{ }^{\circ} \mathrm{C}$ higher $T_{\mathrm{M}}$ value than the $N$-deglycosylated enzyme, which confirms that glycosylation enhances 
Table 2 Substrate scope of PeAAO2. Generated $\mathrm{H}_{2} \mathrm{O}_{2}$ formed upon substrate oxidation was detected in a coupled ABTS-HRP assay. Activity towards benzyl alcohol was set to $100 \%$

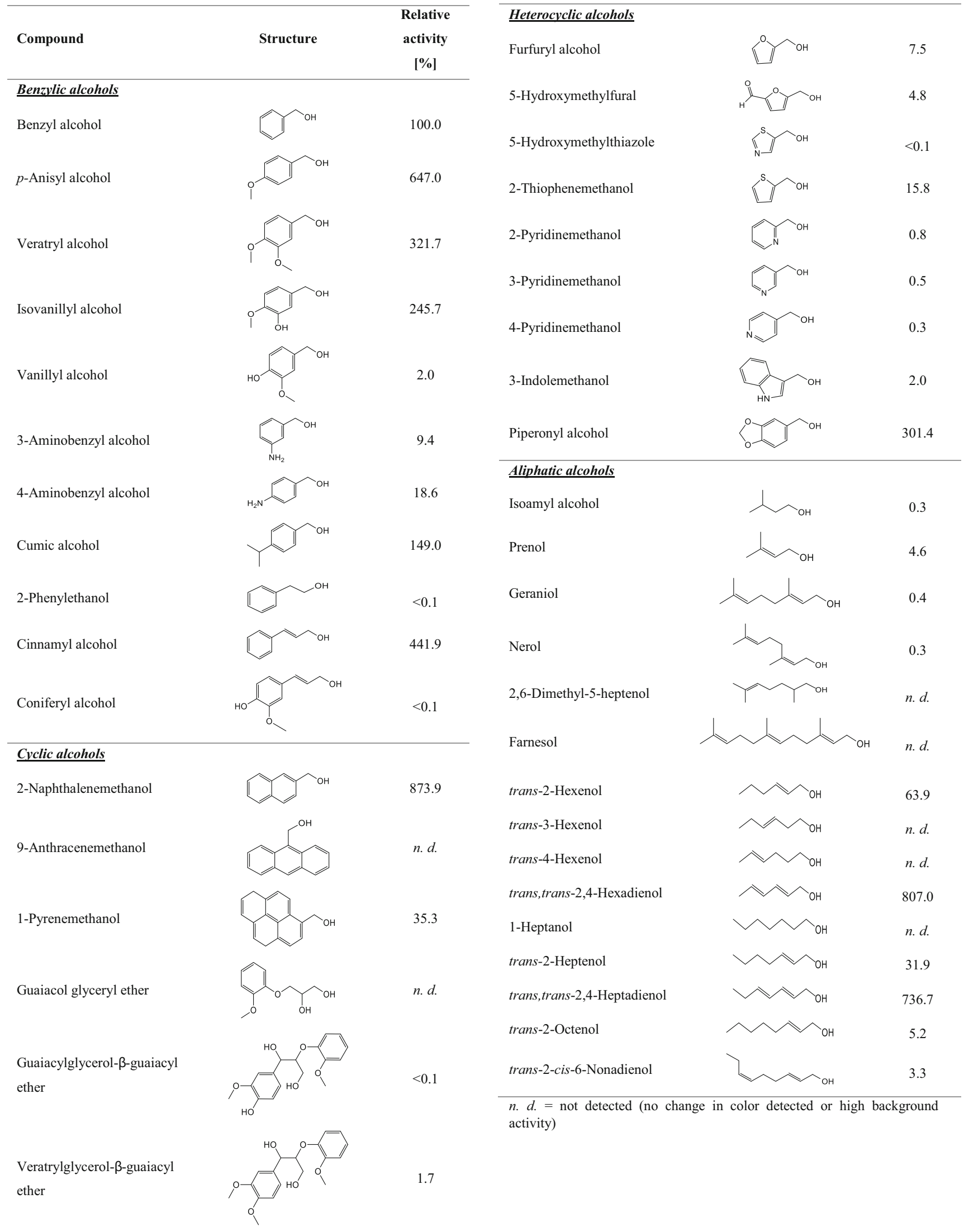


Table 3 Kinetic constants of $P e A A O 2$ compared with those of other AAOs

\begin{tabular}{|c|c|c|c|c|}
\hline & & $\begin{array}{l}\text { PeAAO2 from } \\
P . \text { eryngii expressed in } \\
P . \text { pastoris }^{\mathrm{a}}\end{array}$ & $\begin{array}{l}\text { PeAAO from } \\
\text { P. eryngii expressed } \\
\text { in A. nidulans }{ }^{b}\end{array}$ & $\begin{array}{l}\text { PeAAO FX9 } \\
\text { variant from } P \text {. eryngii } \\
\text { expressed in } P \text {. pastoris }\end{array}$ \\
\hline \multirow[t]{3}{*}{ p-Anisyl alcohol } & $K_{\mathrm{M}}(\mu \mathrm{M})$ & $24.3 \pm 0.8$ & 27 & 37 \\
\hline & $k_{\text {cat }}\left(\mathrm{s}^{-1}\right)$ & $59.2 \pm 0.04$ & 142 & 70 \\
\hline & $k_{\text {cat }} / K_{\mathrm{M}}\left(\mathrm{mM}^{-1} \mathrm{~s}^{-1}\right)$ & 2436 & 5230 & 1909 \\
\hline \multirow[t]{3}{*}{ Benzyl alcohol } & $K_{\mathrm{M}}(\mu \mathrm{M})$ & $599.6 \pm 18.7$ & 632 & 440 \\
\hline & $k_{\mathrm{cat}}\left(\mathrm{s}^{-1}\right)$ & $12.8 \pm 0.01$ & 30 & 34 \\
\hline & $k_{\mathrm{cat}} / K_{\mathrm{M}}\left(\mathrm{mM}^{-1} \mathrm{~s}^{-1}\right)$ & 21.39 & 47 & 78 \\
\hline \multirow[t]{3}{*}{ Cinnamyl alcohol } & $K_{\mathrm{M}}(\mu \mathrm{M})$ & $2740 \pm 103$ & n.d. & n.d. \\
\hline & $k_{\text {cat }}\left(\mathrm{s}^{-1}\right)$ & $125.5 \pm 0.1$ & n.d. & n.d. \\
\hline & $k_{\text {cat }} / K_{\mathrm{M}}\left(\mathrm{mM}^{-1} \mathrm{~s}^{-1}\right)$ & 45.80 & n.d. & n.d. \\
\hline \multirow[t]{3}{*}{ Cumic alcohol } & $K_{\mathrm{M}}(\mu \mathrm{M})$ & $1912 \pm 42.4$ & n.d. & n.d. \\
\hline & $k_{\text {cat }}\left(\mathrm{s}^{-1}\right)$ & $160.8 \pm 0.1$ & n.d. & n.d. \\
\hline & $k_{\mathrm{cat}} / K_{\mathrm{M}}\left(\mathrm{mM}^{-1} \mathrm{~s}^{-1}\right)$ & 84.1 & n.d. & n.d. \\
\hline \multirow[t]{3}{*}{ trans,trans-2,4-hexadienol } & $K_{\mathrm{M}}(\mu \mathrm{M})$ & $143.6 \pm 11.5$ & 94 & 106 \\
\hline & $k_{\text {cat }}\left(\mathrm{s}^{-1}\right)$ & $68.8 \pm 0.05$ & 119 & 89 \\
\hline & $k_{\mathrm{cat}} / K_{\mathrm{M}}\left(\mathrm{mM}^{-1} \mathrm{~s}^{-1}\right)$ & 479.3 & 1270 & 840 \\
\hline \multirow[t]{3}{*}{ Piperonyl alcohol } & $K_{\mathrm{M}}(\mu \mathrm{M})$ & $59.1 \pm 3.0$ & n.d. & n.d. \\
\hline & $k_{\text {cat }}\left(\mathrm{s}^{-1}\right)$ & $35.5 \pm 0.02$ & n.d. & n.d. \\
\hline & $k_{\mathrm{cat}} / K_{\mathrm{M}}\left(\mathrm{mM}^{-1} \mathrm{~s}^{-1}\right)$ & 600.2 & n.d. & n.d. \\
\hline \multirow[t]{3}{*}{ Veratryl alcohol } & $K_{\mathrm{M}}(\mu \mathrm{M})$ & $446.6 \pm 7.5$ & 540 & 410 \\
\hline & $k_{\text {cat }}\left(\mathrm{s}^{-1}\right)$ & $47.2 \pm 0.03$ & 114 & 57 \\
\hline & $k_{\text {cat }} / K_{\mathrm{M}}\left(\mathrm{mM}^{-1} \mathrm{~s}^{-1}\right)$ & 105.7 & 210 & 139 \\
\hline
\end{tabular}

n.d. not determined

${ }^{\mathrm{a}}$ (This study), $100 \mathrm{mM}$ sodium phosphate buffer $\mathrm{pH}$ 6.0. $25^{\circ} \mathrm{C}$, all measurements in triplicate

${ }^{\mathrm{b}}$ (Ferreira et al. 2006), $100 \mathrm{mM}$ sodium phosphate buffer $\mathrm{pH} 6.0,24^{\circ} \mathrm{C}$

${ }^{\mathrm{c}}$ (Viña-Gonzalez et al. 2018), $100 \mathrm{mM}$ sodium phosphate buffer $\mathrm{pH} 6.0,25^{\circ} \mathrm{C}$

thermostability (Wang et al. 1996). Indeed, the glycosylated PeAAO2 exhibited $90 \%$ of residual activity after $1 \mathrm{~h}$ incubation at $50{ }^{\circ} \mathrm{C}$ and showed a $T_{50}$ value of $62.1{ }^{\circ} \mathrm{C}$, which is comparable with that of hyperglycosylated $P e A A O$ variant FX9 expressed in S. cerevisiae $\left(63.0^{\circ} \mathrm{C}\right)$ (Viña-Gonzalez et al. 2018). In contrast, PeAAO purified from inclusion bodies from $E$. coli lacks glycosylation and shows a much lower thermostability compared to $\mathrm{PeAAO} 2$ and $\mathrm{PeAAO}$ variant FX9 with around $20 \%$ of residual activity after $50 \mathrm{~min}$ incubation at $50{ }^{\circ} \mathrm{C}$ and a $T_{50}$ of $47.5^{\circ} \mathrm{C}$ (Ruiz-Dueñas et al. 2006; Viña-Gonzalez et al. 2015). PeAAO2 showed high stability within a wide $\mathrm{pH}$ range between $\mathrm{pH} 3.0$ and 9.0, which is similar to another glycosylated Pleurotus AAO (ViñaGonzalez et al. 2015). Since the E. coli-derived PeAAO showed considerably lower $\mathrm{pH}$ stability, especially at pH 3.0 and above pH 9.0 (Viña-Gonzalez et al. 2015), we assume that high pH stability of AAOs is also attributed to glycosylation.

\section{Substrate scope of PeAAO2}

PeAAO2 was found to oxidize a broad range of chemically diverse primary alcohols, including compounds not yet reported as substrates for AAOs. The substrate preference was dependent on the present aromatic substitution groups and the number of conjugated double bonds, as reported also for other Pleurotus AAOs (Bourbonnais and Paice 1988; Guillén et al. 1992). A methoxy-group at the para-position of the aromatic ring seems to be crucial for efficient substrate oxidation as shown for $p$-anisyl alcohol, veratryl alcohol, and isovanillyl alcohol when compared with the non-substituted benzyl alcohol. A para-isopropyl group in cumic alcohol had also a beneficial effect leading to a 1.5 -times higher relative activity than with benzyl alcohol. These results allow to suggest that the presence of an electron-donating group at para-position had a positive effect on enzyme activity. Presumably, enhanced electron density at the aromatic ring facilitates oxidation of the primary alcohol group. The presence of an amino group 
in para-position in 4-aminobenzyl alcohol reduced substrate acceptance by a factor of 5 , which might be explained by its protonated state at neutral $\mathrm{pH}$, which makes this group electron-withdrawing. The presence of unsaturated bonds in the side chains of (aryl) alkyl alcohols, and thus extension of the conjugated double bond system as in cinnamyl alcohol had tremendous effects on substrate oxidation resulting in 4-times higher relative activity compared to benzyl alcohol. Although coniferyl alcohol contains an unsaturated side chain, its oxidation was barely detectable as was also seen for the metamethoxy-para-hydroxy substituted vanillyl alcohol. In both substrates, a methoxy-group at meta-position of the aromatic ring act as electron-withdrawing group. Interestingly, the presence of a para-hydroxyl group has been previously reported to negatively influence the oxidation reaction by an AAO (Guillén et al. 1992). Obviously, the influence of the substrate binding site on substrate specificity and enzyme activity should be considered as well.

Expansion of the aromatic system to two condensed aromatic rings in 2-naphthalenemethanol led to the highest activity detected among all substrates, which is in accordance with activity of PeAAO (Guillén et al. 1992). However, further extension of the ring system as in the tricyclic 9anthracenemethanol did not result in detectable substrate oxidation, while the four-membered ring of 1-pyrenemethanol was oxidized with one third of activity as compared with benzyl alcohol. The acceptance of 9-anthracenemethanol by $P e A A O$ could be affected by steric hindrances: The primary alcohol group is located in a less exposed position as compared with 2-naphthalenemethanol or 1-pyrenemethanol, thereby not reaching into the active site cavity.

Various heterocyclic compounds derived from benzodioxole, furan, indole, pyridine, and thiophene were tested as substrates and were accepted by $P e A A O 2$ at least to some extent. Most remarkably, the benzodioxole derivative piperonyl alcohol was oxidized with a 3-times higher relative activity than benzyl alcohol. As described for veratryl alcohol (Guillén et al. 1992), the oxygen atoms in piperonyl alcohol most likely produce an electrondonating effect, leading to a higher electron density at the primary hydroxyl group, resulting in favored oxidation of the primary alcohol group. PeAAO2's activity was rather low towards the furan-derived 5-hydroxymethylfurfural (5-HMF) which has been investigated in several studies as starting material for the production of bio-based 2,5furandicarboxylic acid (FDCA) as precursor for plastics with involvement of an AAO (Carro et al. 2014; Karich et al. 2018; Serrano et al. 2019a; Viña-Gonzalez et al. 2020). The sulfur-containing 2-thiophenemethanol was converted with a relative activity of $16 \%$ and was the first described sulfuric compound accepted by an AAO. Several nitrogen-containing heterocyclic compounds including indole and pyridine derivatives were converted by $\mathrm{PeAAO} 2$ only to less than $2 \%$. Even though the substrate oxidation was rather low with some of these heterocyclic compounds, the results show that $\mathrm{PeAAO} 2$ is capable of oxidizing chemically diverse primary alcohols.

Linear primary alcohols can serve as AAO substrates, if the alcohol group is in conjugation with double bonds, like in trans,trans-2,4-hexadienol (Guillén et al. 1992) or trans,trans-2,4-heptadienol, which led to the second and third highest relative activity of all tested compounds. The reduction of number of conjugated double bonds as in trans-2hexenol and trans-2-heptenol resulted in 12-fold and 23-fold lower relative activity than with their counterparts trans,trans2,4-hexadienol and trans,trans-2,4-heptadienol. The elongation of the linear unsaturated alcohol to $\mathrm{C} 8$ and $\mathrm{C} 9$ as in trans2-octenol and trans-2-cis-6-nonadienol reduced enzyme activity further. Nevertheless, oxidation of the latter substrate results in "the violet leaf aldehyde" or "cucumber aldehyde," which is the major aroma component in fresh cucumber (Schieberle et al. 1990) and among the most potent fragrance compounds (Surburg and Panten 2006). This volatile compound is also present in different plant materials including extracts of violet leafs and fruits such as cherry and mango (Pino and Mesa 2006; Schmid and Grosch 1986). Several other aliphatic alcohols like geraniol, nerol, and prenol were accepted by $P e A A O 2$ and converted with activities below 5\%, possibly due to steric limitations caused by their branched aliphatic structure.

Substrate affinities of $P e A A O 2$ for $p$-anisyl alcohol, benzyl alcohol, trans,trans-2,4-hexadienol, and veratryl alcohol were in the same range as for the closely related $P$. eryngii PeAAO expressed in A. nidulans and its FX9 variant expressed in $P$. pastoris (Table 2). All three enzymes showed the highest catalytic efficiency for $p$-anisyl alcohol. Glycosylated wildtype PeAAO with $14 \%$ carbohydrate content, expressed in A. nidulans (Varela et al. 2001), showed higher catalytic efficiencies for most substrates compared to PeAAO2 with $30 \%$ carbohydrate content and the poorly glycosylated PeAAO variant FX9 (Viña-Gonzalez et al. 2018). Lower activity of variant FX9 compared to PeAAO might be caused by introduced mutations. On the other hand, it has been shown that non-glycosylated $P e A A O$ derived from $E$. coli showed lower catalytic efficiencies than glycosylated PeAAO (Ruiz-Dueñas et al. 2006). Besides having a positive effect on $\mathrm{pH}$ and thermal stability, catalytic efficiency of AAOs seems to be positively influenced by glycosylation as well. Other AAOs that have been expressed in $P$. pastoris include Coprinopsis cinerea (CcAAO) (Tamaru et al. 2018) and Ustilago maydis AAO (UmAAO) (Couturier et al. 2016). UmAAO exhibited the highest catalytic efficiency towards $p$-anisyl alcohol similar to Pleurotus AAOs, while for CcAAO, the highest catalytic efficiency was described for benzyl alcohol. These results indicate different substrate specificities among different fungal AAOs. 
As far as to our knowledge, the acceptance of piperonyl alcohol and cumic alcohol, as well as of amino-substituted and thiophene-derived primary alcohols and 1pyrenemethanol, has not been reported for AAOs so far, and extends our knowledge of the substrate scope of arylalcohol oxidases. The second highest catalytic efficiency of $P e A A O 2$ was observed with piperonyl alcohol, proving that this compound is a promising substance for biocatalytic conversions, as its aldehyde is the fragrance compound piperonal used in cosmetics, and flavor and fragrance industry. Piperonal has a sweet-flowery and spicy odor and is present in essential oils of flowers of the Heliotropium genus (Bellardita et al. 2014; Santos et al. 2003) and thus also termed as "heliotropin". Due to its benzodioxole functionality, it also serves as intermediate for several products of industrial importance, such as insecticides, pesticides, and pharmaceutical products, e.g., used in the synthesis of new drugs against Alzheimer's disease (Brum et al. 2019; Santos et al. 2004; Wang et al. 2019).

The highest turnover rate for $\mathrm{PeAAO} 2$ was observed for cumic alcohol oxidation to the bioactive compound cuminaldehyde, a major constituent of seed oil of Cuminum cyminum plant (Lee 2005; Li and Jiang 2004). Beyond the use of $C$. cyminum seeds as spice in traditional cuisines, different beneficial effects have been attributed to its use, including anticancer, antidiabetic, and neuroprotective effects that have been linked to cuminaldehyde as its active ingredient (Lee 2005; Morshedi et al. 2015; Patil et al. 2013; Tsai et al. 2016). The biocatalytic production of cuminaldehyde has not been described yet and the oxidation of cumic alcohol to cuminaldehyde using $\mathrm{PeAAO} 2$ seems to be a feasible route.

In summary, high-yield production of $P e A A O 2$ in $P$. pastoris together with its broad substrate spectrum and high stability renders this enzyme a promising candidate for biotechnological applications. Additionally, the production of piperonal and cuminaldehyde by $\mathrm{PeAAO} 2$ further expands the use of this biocatalyst for the production of intermediates for pharmaceutical products, as well as of flavors and fragrances.

Authors' contributions $\mathrm{NJ}$ designed and conducted the experiments, evaluated the results, and drafted the manuscript. KK and VBU gave advices in the research work, helped in drafting the manuscript, and revised the manuscript. All authors read and approved the final manuscript.

Funding Open Access funding provided by Projekt DEAL. The scientific activities of the Bioeconomy Science Center were financially supported by the Ministry of Innovation, Science and Research within the framework of the North Rhine-Westphalia, Germany, NRW-Strategieprojekt BioSC (No. 313/323-400-002 13).

Data availability All data on which the conclusions were drawn are presented in this study.

\section{Compliance with ethical standards}

Conflict of interest The authors declare that they have no conflict of interest.

Ethical approval This article does not contain any studies with human participants or animals performed by any of the authors.

Consent to participate Not applicable.

Consent for publication Not applicable.

Open Access This article is licensed under a Creative Commons Attribution 4.0 International License, which permits use, sharing, adaptation, distribution and reproduction in any medium or format, as long as you give appropriate credit to the original author(s) and the source, provide a link to the Creative Commons licence, and indicate if changes were made. The images or other third party material in this article are included in the article's Creative Commons licence, unless indicated otherwise in a credit line to the material. If material is not included in the article's Creative Commons licence and your intended use is not permitted by statutory regulation or exceeds the permitted use, you will need to obtain permission directly from the copyright holder. To view a copy of this licence, visit http://creativecommons.org/licenses/by/4.0/.

\section{References}

Aliverti A, Curti B, Vanoni MA (1999) Identifying and quantitating FAD and FMN in simple and in iron-sulfur-containing flavoproteins. In: Chapman SK, Reid GA (eds) Flavoprotein Protocols. Humana Press, Totowa, pp 9-23

Arregui L, Ayala M, Gómez-Gil X, Gutiérrez-Soto G, Hernández-Luna CE, Herrera de Los Santos M, Levin L, Rojo-Domínguez A, Romero-Martínez D, Saparrat MCN, Trujillo-Roldán MA, ValdezCruz NA (2019) Laccases: structure, function, and potential application in water bioremediation. Microb Cell Factories 18(1):200. https://doi.org/10.1186/s12934-019-1248-0

Bellardita M, Loddo V, Palmisano G, Pibiri I, Palmisano L, Augugliaro V (2014) Photocatalytic green synthesis of piperonal in aqueous TiO2 suspension. Appl Catal B 144:607-613. https://doi.org/10.1016/j. apcatb.2013.07.070

Bourbonnais R, Paice MG (1988) Veratryl alcohol oxidases from the lignin-degrading basidiomycete Pleurotus sajor-caju. Biochem J 255(2):445-450. https://doi.org/10.1042/bj2550445

Bradford MM (1976) A rapid and sensitive method for the quantitation of microgram quantities of protein utilizing the principle of protein-dye binding. Anal Biochem 72:248-254. https://doi.org/10.1016/00032697(76)90527-3

Brum JOC, Neto DCF, de Almeida JSFD, Lima JA, Kuca K, França TCC, Figueroa-Villar JD (2019) Synthesis of new quinolinepiperonal hybrids as potential drugs against Alzheimer's disease. Int J Mol Sci 20(16):3944. https://doi.org/10.3390/ijms20163944

Carro J, Ferreira P, Rodríguez L, Prieto A, Serrano A, Balcells B, Ardá A, Jiménez-Barbero J, Gutiérrez A, Ullrich R, Hofrichter M, Martínez AT (2014) 5-hydroxymethylfurfural conversion by fungal arylalcohol oxidase and unspecific peroxygenase. FEBS J 282:32183229. https://doi.org/10.1111/febs.13177

Childs BRE, Bardsley WG (1975) The steady-state kinetics of peroxidase with 2,2'-azino-di-(3-ethylbenzthiazoline-6-sulphonic acid) as chromogen. Biochem J 145:93-103. https://doi.org/10.1042/bj1450093 
Couturier M, Mathieu Y, Li A, Navarro D, Drula E, Haon M, Grisel S, Ludwig R, Berrin JG (2016) Characterization of a new aryl-alcohol oxidase secreted by the phytopathogenic fungus Ustilago maydis. Appl Microbiol Biotechnol 100:697-706. https://doi.org/10.1007/ s00253-015-7021-3

de Almeida TP, van Schie MMCH, Ma A, Tieves F, Younes SHH, Fernández-Fueyo E, Arends IWCE, Riul A, Hollmann F (2019) Efficient aerobic oxidation of trans-2-hexen-1-ol using the aryl alcohol oxidase from Pleurotus eryngii. Adv Synth Catal 361:2668 2672. https://doi.org/10.1002/adsc. 201801312

Falade AO, Nwodo UU, Iweriebor BC, Green E, Mabinya LV, Okoh AI (2016) Lignin peroxidase functionalities and prospective applications. Microbiologyopen 6:1-14. https://doi.org/10.1002/mbo3.394

Falade AO, Mabinya LV, Okoh AI, Nwodo UU (2018) Ligninolytic enzymes: versatile biocatalysts for the elimination of endocrinedisrupting chemicals in wastewater. Microbiologyopen 7(6): e00722. https://doi.org/10.1002/mbo3.722

Fernández IS, Ruíz-Duẽas FJ, Santillana E, Ferreira P, Martínez MJ, Martínez ÁT, Romero A (2009) Novel structural features in the GMC family of oxidoreductases revealed by the crystal structure of fungal aryl-alcohol oxidase. Acta Crystallogr Sect D Biol Crystallogr 65:1196-1205. https://doi.org/10.1107/ S0907444909035860Ferreira

Ferreira P, Medina M, Guillén F, Martínez MJ, Van Berkel WJH, Martínez AT (2005) Spectral and catalytic properties of arylalcohol oxidase, a fungal flavoenzyme acting on polyunsaturated alcohols. Biochem J 389:731-738. https://doi.org/10.1042/ BJ20041903

Ferreira P, Ruiz-Dueñas FJ, Martínez MJ, Van Berkel WJH, Martínez AT (2006) Site-directed mutagenesis of selected residues at the active site of aryl-alcohol oxidase, an $\mathrm{H}_{2} \mathrm{O}_{2}$-producing ligninolytic enzyme. FEBS J 273:4878-4888. https://doi.org/10.1111/j.17424658.2006.05488.x

Ferreira P, Hernández-Ortega A, Herguedas B, Rencoret J, Gutiérrez A, Martínez MJ, Jiménez-Barbero J, Medina M, Martínez ÁT (2010) Kinetic and chemical characterization of aldehyde oxidation by fungal aryl-alcohol oxidase. Biochem J 425:585-593. https://doi.org/ 10.1042/BJ20091499

Fillat Ú, Ibarra D, Eugenio M, Moreno A, Tomás-Pejó E, MartínSampedro R (2017) Laccases as a potential tool for the efficient conversion of lignocellulosic biomass: a review. Fermentation 3(2):17. https://doi.org/10.3390/fermentation3020017

Forneris F, Orru R, Bonivento D, Chiarelli LR, Mattevi A (2009) ThermoFAD, a Thermofluor $($-adapted flavin ad hoc detection system for protein folding and ligand binding. FEBS J 276:2833-2840. https://doi.org/10.1111/j.1742-4658.2009.07006.x

Galperin I, Javeed A, Luig H, Lochnit G, Rühl M (2016) An aryl-alcohol oxidase of Pleurotus sapidus: heterologous expression, characterization, and application in a 2-enzyme system. Appl Microbiol Biotechnol 100:8021-8030. https://doi.org/10.1007/s00253-016$7567-8$

Gasteiger E, Hoogland C, Gattiker A, Duvaud S, Wilkins MR, Appel RD, Bairoch A (2005) Protein identification and analysis tools on the ExPASy server. In: Walker JM (ed) The proteomics protocols handbook. Humana Press, Totowa, pp 571-607

Grote A, Hiller K, Scheer M, Münch R, Nörtemann B, Hempel DC, Jahn D (2005) JCat: a novel tool to adapt codon usage of a target gene to its potential expression host. Nucleic Acids Res 33:526-531. https:// doi.org/10.1093/nar/gki376

Guillén F, Martínez AT, Martínez MJ (1992) Substrate specificity and properties of the aryl-alcohol oxidase from the ligninolytic fungus Pleurotus eryngii. Eur J Biochem 209:603-611. https://doi.org/10. 1111/j.1432-1033.1992.tb17326.x

Karich A, Kleeberg S, Ullrich R, Hofrichter M (2018) Enzymatic preparation of 2,5-furandicarboxylic acid (FDCA) - a substitute of terephthalic acid — by the joined action of three fungal enzymes.
Microorganisms 6(1):5. https://doi.org/10.3390/ microorganisms6010005

Kirk TK, Farrell RL (1987) Enzymatic "combustion": the microbial degradation of lignin. Annu Rev Microbiol 41:465-505. https://doi.org/ 10.1146/annurev.mi.41.100187.002341

Kukuruzinska MA, Bergh MLE, Jackson BJ (1987) Protein glycosylation in yeast. Annu Rev Biochem 56:915-944. https://doi.org/10.1146/ annurev.bi.56.070187.004411

Laemmli UK (1970) Cleavage of structural proteins during assembly of head of bacteriophage-T4. Nature 227:680-685. https://doi.org/10. 1038/227680a0

Lee HS (2005) Cuminaldehyde: aldose reductase and $\alpha$-glucosidase inhibitor derived from Cuminum cyminum L. seeds. J Agric Food Chem 53(7):2446-2450. https://doi.org/10.1021/jf048451g

Li R, Jiang ZT (2004) Chemical composition of the essential oil of Cuminum cyminum L. from China. Flavour Fragr J 19(4):311313. https://doi.org/10.1002/ffj.1302

Morshedi D, Aliakbari F, Tayaranian-Marvian A, Fassihi A, PanMontojo F, Pérez-Sánchez H (2015) Cuminaldehyde as the major component of Cuminum cyminum, a natural aldehyde with inhibitory effect on alpha-synuclein fibrillation and cytotoxicity. J Food Sci 80(10):H2336-H2345. https://doi.org/10.1111/1750-3841.13016

Patel RN (2018) Biocatalysis for synthesis of pharmaceuticals. Bioorg Med Chem 26(7):1252-1274. https://doi.org/10.1016/j.bmc.2017. 05.023

Patil SB, Takalikar SS, Joglekar MM, Haldavnekar VS, Arvindekar AU (2013) Insulinotropic and $\beta$-cell protective action of cuminaldehyde, cuminol and an inhibitor isolated from Cuminum cyminum in streptozotocin-induced diabetic rats. Br J Nutr 110(8): 1434-1443. https://doi.org/10.1017/S0007114513000627

Pino JA, Mesa J (2006) Contribution of volatile compounds to mango (Mangifera indica L.) aroma. Flavour Fragr J 21(2):207-213. https://doi.org/10.1002/ffj.1703

Rodríguez Couto S, Toca Herrera JL (2006) Industrial and biotechnological applications of laccases: a review. Biotechnol Adv 24:500-513. https://doi.org/10.1016/j.biotechadv.2006.04.003

Ruiz-Dueñas FJ, Ferreira P, Martínez MJ, Martínez AT (2006) In vitro activation, purification, and characterization of Escherichia coli expressed aryl-alcohol oxidase, a unique $\mathrm{H}_{2} \mathrm{O}_{2}$-producing enzyme. Protein Expr Purif 45(1):191-199. https://doi.org/10.1016/j.pep. 2005.06.003

Sannia G, Limongi P, Cocca E, Buonocore F, Nitti G, Giardina P (1991) Purification and characterization of a veratryl alcohol oxidase enzyme from the lignin degrading basidiomycete Pleurotus ostreatus. Biochim Biophys Acta 1073:114-119. https://doi.org/10.1016/ 0304-4165(91)90190-R

Santos AS, Pereira N, Da Silva IM, Sarquis MIM, Antunes OAC (2003) Microbiologic oxidation of isosafrole into piperonal. Appl Biochem Biotechnol 105-108:649-657. https://doi.org/10.1385/abab:107:13:649

Santos AS, Pereira N, Da Silva IM, Sarquis MIM, Antunes OAC (2004) Peroxidase catalyzed microbiological oxidation of isosafrol into piperonal. Process Biochem 39(12):2269-2275. https://doi.org/10. 1016/j.procbio.2003.11.019

Schieberle P, Ofner S, Grosch W (1990) Evaluation of potent odorants in cucumbers (Cucumis sativus) and muskmelons (Cucumis melo) by aroma extract dilution analysis. J Food Sci 55(1):193-195. https:// doi.org/10.1111/j.1365-2621.1990.tb06050.x

Schmid W, Grosch W (1986) Quantitative Analyse flüchtiger Aromastoffe mit hohen Aromawerten in Sauerkirschen (Prunus cerasus L.), Süßkirschen (Prunus avium L.) und Kirschkonfitüren. Z Lebensm Unters Forsch 183(1):39-44. https://doi.org/10.1007/ BF01027592

Serrano A, Calviño E, Carro J, Sánchez-Ruiz MI, Cañada FJ, Martínez AT (2019a) Complete oxidation of hydroxymethylfurfural to 
furandicarboxylic acid by aryl-alcohol oxidase. Biotechnol Biofuels 12:217. https://doi.org/10.1186/s13068-019-1555-Z

Serrano A, Sancho F, Viña-González J, Carro J, Alcalde M, Guallar V, Martínez AT (2019b) Switching the substrate preference of fungal aryl-alcohol oxidase: towards stereoselective oxidation of secondary benzyl alcohols. Catal Sci Technol 9:833-841. https://doi.org/10. 1039/C8CY02447B

Sheldon RA, Woodley JM (2018) Role of biocatalysis in sustainable chemistry. Chem Rev 118(2):801-838. https://doi.org/10.1021/acs. chemrev.7b00203

Stanzione I, Pezzella C, Giardina P, Sannia G, Piscitelli A (2020) Beyond natural laccases: extension of their potential applications by protein engineering. Appl Microbiol Biotechnol 104:915-924. https://doi. org/10.1007/s00253-019-10147-z

Surburg H, Panten J (2006) Common fragrance and flavor materials, 5th edn. Wiley-VCH, Weinheim

Tamaru Y, Umezawa K, Yoshida M (2018) Characterization of an arylalcohol oxidase from the plant saprophytic basidiomycete Coprinopsis cinerea with broad substrate specificity against aromatic alcohols. Biotechnol Lett 40(7):1077-1086. https://doi.org/10. 1007/s10529-018-2534-3

Tsai KD, Liu YH, Chen TW, Yang SM, Wong HY, Cherng J, Chou KS, Cherng JM (2016) Cuminaldehyde from Cinnamomum verum induces cell death through targeting topoisomerase 1 and 2 in human colorectal adenocarcinoma COLO 205 cells. Nutrients 8(6):318. https://doi.org/10.3390/nu8060318

Van Schie MMCH, De Almeida TP, Laudadio G, Tieves F, FernándezFueyo E, Noël T, Arends IWCE, Hollmann F (2018) Biocatalytic synthesis of the Green Note trans-2-hexenal in a continuous-flow microreactor. Beilstein J Org Chem 14:697-703. https://doi.org/10. 3762/bjoc. 14.58

Varela E, Martínez AT, Martínez MJ (1999) Molecular cloning of arylalcohol oxidase from the fungus Pleurotus eryngii, an enzyme involved in lignin degradation. Biochem J 341:113. https://doi.org/10. 1042/0264-6021:3410113

Varela E, Böckle B, Romero A, Martínez AT, Martínez MJ (2000a) Biochemical characterization, cDNA cloning and protein crystallization of aryl-alcohol oxidase from Pleurotus pulmonarius. Biochim Biophys Acta 1476:129-138. https://doi.org/10.1016/ S0167-4838(99)00227-7

Varela E, Martínez MJ, Martínez AT (2000b) Aryl-alcohol oxidase protein sequence: a comparison with glucose oxidase and other FAD oxidoreductases. Biochim Biophys Acta 1481:202-208. https://doi. org/10.1016/S0167-4838(00)00127-8

Varela E, Guillén F, Martínez ÁT, Martínez MJ (2001) Expression of Pleurotus eryngii aryl-alcohol oxidase in Aspergillus nidulans: purification and characterization of the recombinant enzyme. Biochim Biophys Acta 1546:107-113. https://doi.org/10.1016/S01674838(00)00301-0

Viña-Gonzalez J, Alcalde M (2020) Directed evolution of the arylalcohol oxidase: beyond the lab bench. Comput Struct Biotechnol J 18:1800-1810. https://doi.org/10.1016/j.csbj.2020.06.037

Viña-Gonzalez J, Martinez AT, Guallar V, Alcalde M (2020) Sequential oxidation of 5-hydroxymethylfurfural to furan-2,5-dicarboxylic acid by an evolved aryl-alcohol oxidase. Biochim Biophys Acta 1868(1): 140293. https://doi.org/10.1016/j.bbapap.2019.140293

Viña-Gonzalez J, Gonzalez-Perez D, Ferreira P, Martinez AT, Alcalde M (2015) Focused directed evolution of aryl-alcohol oxidase in Saccharomyces cerevisiae by using chimeric signal peptides. Appl Environ Microbiol 81(18):6451-6462. https://doi.org/10.1128/ AEM.01966-15

Viña-Gonzalez J, Elbl K, Ponte X, Valero F, Alcalde M (2018) Functional expression of aryl-alcohol oxidase in Saccharomyces cerevisiae and Pichia pastoris by directed evolution. Biotechnol Bioeng 115(7):1666-1674. https://doi.org/10.1002/bit.26585

Viña-Gonzalez J, Jimenez-Lalana D, Sancho F, Serrano A, Martinez AT, Guallar V, Alcalde M (2019) Structure-guided evolution of aryl alcohol oxidase from Pleurotus eryngii for the selective oxidation of secondary benzyl alcohols. Adv Synth Catal 361:2514-2525. https://doi.org/10.1002/adsc.201900134

Wang C, Eufemi M, Turano C, Giartosio A (1996) Influence of the carbohydrate moiety on the stability of glycoproteins. Biochemistry 35(23):7299-7307. https://doi.org/10.1021/ bi9517704

Wang S, Bao L, Song D, Wang J, Cao X (2019) Heterocyclic lactam derivatives containing piperonyl moiety as potential antifungal agents. Bioorg Med Chem Lett 29(20):126661. https://doi.org/10. 1016/j.bmcl.2019.126661

Publisher's note Springer Nature remains neutral with regard to jurisdictional claims in published maps and institutional affiliations. 